\title{
Bases para unha cronoloxía da literatura galega (1801-1900)
}

\author{
Elements for a Chronology of Galician Literature \\ (1801-1900)
}

\section{Teresa LóPEZ}

Universidade da Coruña

Departamento de Galego-Portugués, Francés e Lingüística

teresa@udc.es

[recibido 06/11/2014, aceptado 26/01/2015]

\section{RESUMO}

Presentación do proxecto de investigación en curso CROLIGA. Cronoloxía da literatura galega (1801-1900), que ten como obxecto elaborar unha base de datos das obras publicadas en volume no período citado para póla a disposición pública a través dun portal web. Explícanse as súas características, as fases de desenvolvemento e os resultados obtidos até a data.

PALABRAS CHAVE: Cronoloxía, literatura galega, século XIX, CROLIGA.

\section{RESUMEN}

Presentación del proyecto de investigación en curso CROLIGA. Cronoloxía da literatura galega (1801-1900), que tiene como objetivo elaborar una base de datos de las obras publicadas en volumen en el período citado para ponerla a disposición pública a través de un portal web. Se explican sus características, las fases de desarrollo y los resultados obtenidos hasta la fecha.

PALABRAS CLAVE: Cronología, literatura gallega, siglo XII, CROLIGA.

\section{ABSTRACT}

The aim of this presentation is to describe the research project CROLIGA, A Chronology of Galician Literature (1801-1900). This project intends to build an extensive database of works published in the 19th century and make it publicly available online. The presentation will be particularly concerned with the characteristics, stages of development and current results of this project.

KEY WORDS: Chronology, Galician literature, 19th century, CROLIGA.

López, T. (2015): “Bases para unha cronoloxía da literatura galega (1801-1900)”, Madrygal (Madr.), 18, Núm. Especial: 211-220. 
CROLIGA. Cronoloxía da literatura galega (1801-1900) (FFI2012-37891) é un proxecto de investigación subvencionado polo Subprograma de Proxectos de Investigación Fundamental do Plan Nacional de $\mathrm{I}+\mathrm{D}+\mathrm{i}$ do Ministerio de Economía e Competitividade do Goberno de España. O proxecto, en curso, é responsabilidade dunha equipa de profesorado da Facultade de Filoloxía da Universidade da Coruña ${ }^{1}$.

O seu obxectivo é elaborar unha base de datos das obras en lingua galega publicadas en volume no período citado e disponibilizala para a consulta pública a través dun portal web específico, que terá o enderezo: http://croliga. udc.es (Fig. 1) $)^{2}$.

Con este proxecto pretendemos ensaiar, pór a punto e medir a validez da metodoloxía de traballo para ser aplicada ao conxunto da literatura galega contemporánea. Somos conscientes de que, tal como está definido o proxecto, estamos a falar de "literatura" como sinónimo de "produción literaria"; a nosa posición

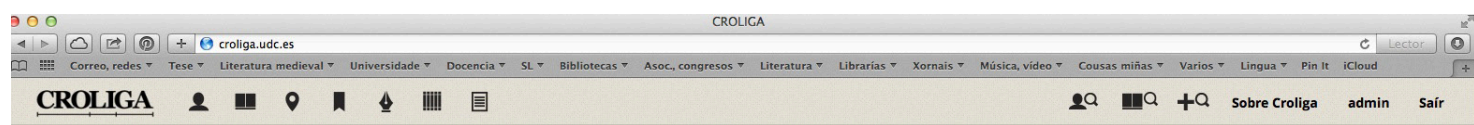

\section{Cronoloxía da literatura galega (1801- 1900)}

Proxecto de investigación FF12012-37891

Subprograma de Proxectos de Irvestigación Fundamental non Orientada, Programa Nacional de Proxectos

de Investigación Fundamental, Vi Plan Nacional de Investigación Cientifíca, Desarrollo e Innovación

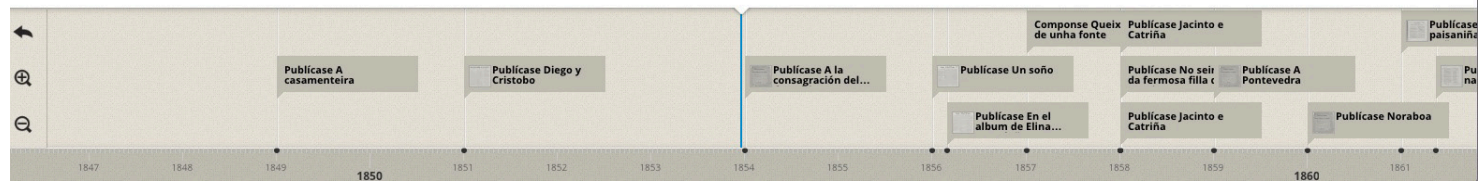

Figura 1

${ }^{1} \mathrm{O}$ equipo está integrado por Luís Caparrós Esperante, Leticia Eirín, Teresa López (investigadora principal) e Carlos Paulo Martínez Pereiro (con dedicación parcial). Desde setembro traballa como investigador contratado a tempo parcial o licenciado Diego Rivadulla Costa. A presente publicación enmárcase neste proxecto.

${ }^{2}$ Nesta altura, outubro de 2014, o portal non é de acceso público. Esperamos que si o sexa no momento en que estas páxinas se publiquen. 
pode parecer "textocéntrica" mais, en realidade, é tan só unha opción á hora de delimitar o obxecto da investigación, para que sexa posíbel levala a termo completamente no período de tempo previsto e cos medios relativamente escasos de que dispomos. Optando por un obxectivo conscientemente restrito, pensamos que garantimos tanto a calidade da información incluída como que o traballo realizado sente unhas bases sólidas a partir das que se poidan ampliar os contornos da cronoloxía, en diversos sentidos.

O noso propósito é estabelecer datacións rigorosas para as obras do período citado, ordenando no tempo (até onde for posíbel) a produción literaria, e que estes datos, comprobados, organizados e completados, poidan contribuír para (re)explicar a literatura galega do século XIX. Mesmo limitando a información levantada á produción textual, os datos recollidos lévannos necesariamente a outros ámbitos, o dos/das produtores/as, en primeiro lugar, mais tamén achegan información sobre receptores/as, mercado editorial, ou repertorio, como veremos.

Na páxina de entrada ao portal (Fig. 1), ademais das referencias que identifican o proxecto, figura unha liña cronolóxica temporal lineal, pola que se pode navegar, á procura dun ano concreto. Na liña aparecen as obras publicadas (e/ou compostas ${ }^{3}$ ) no período temporal que visualicemos: clicando en cada obra, despregarase a súa ficha. A información recollida en CROLIGA poderá tamén recuperarse desde esta páxina de entrada a través dun sistema de procuras, que permitirá realizar buscas específicas por autor/autora, por obra e, nunha terceira caixa, nos restantes campos de que se compón a base (editora, publicación periódica, xénero, lugar de publicación).

Este portal web é resultado de visualizar a base de datos coa que traballamos. Esta escolla permítenos dispor dunha ferramenta que non só armacena a información, senón que permite revisala, completala e modificala en calquera momento, e disponibilizar o portal para a súa consulta pública ao tempo que continúa a incorporación de datos.

A opción por esta ferramenta informática obrigounos a mudar determinados aspectos da metodoloxía de traballo inicialmente prevista, mais esas mudanzas serviron, pensamos, para enriquecer a información que ofrecemos con elementos complementares, por exemplo de carácter gráfico, ou coa inclusión de hipervínculos, como explicaremos máis adiante.

Para cada texto recóllese a información seguinte: autor/a (nome completo, data e lugar de nacemento e falecemento), sinatura no texto (vinculado ao anterior), título, xénero literario (diálogo, ensaio, narrativa, poesía, prosa, teatro) ${ }^{4}$, data de composición (cando se coñece), data de publicación e lugar de publicación (volume, cabeceira da prensa periódica, etc.), imprenta e/ou editora. Para cada obra vincúlanse as diferentes publicacións con relevancia ecdótica ou editorial ${ }^{5}$ e recóllense os datos relativos a cada unha delas (data e lugar de publicación, se foi en volume ou na prensa periódica, imprenta e/ou editora).

\footnotetext{
${ }^{3} \mathrm{Na}$ liña cronolóxica as obras están ordenadas pola data de publicación. Só nos casos en que a súa publicación se realizou fóra dos límites do século XIX, a referencia na liña temporal é a data de composición. Por suposto, en todos os casos recóllese a data de composición (cando é coñecida) e de edición na ficha de cada obra.

${ }^{4}$ Indicamos o elenco de xéneros definidos neste momento. Na captura de pantalla figuran tamén xéneros que se incorporaron non para catalogar "textos", e si volumes (p. ex. "miscelánea"). Conforme avancemos na incorporación de textos, non descartamos realizar modificacións neste apartado. Debemos facer constar que a opción "publicacións periódicas" non se corresponde con este criterio, e que foi incluída aquí temporalmente por necesidades de xestión da información: na mellora da ferramenta de xestión que estamos a realizar agora mesmo vai ser eliminada deste apartado para lle dar entidade propia.

${ }^{5}$ Falamos de relevancia ecdótica para aquelas publicacións dun texto que conteñen variantes textuais; e de relevancia editorial para os casos en que un texto dado se publicou nun volume relevante para a construción do canon (p. ex. o Álbum de la Caridad).
} 
Nas Figs. 2 e 3 mostramos os campos da xestión de obras.

Como organizamos o levantamento da información que logo incluiremos na cronoloxía? En primeiro lugar, estabelecemos unha relación exhaustiva de bibliografía secundaria: historias da literatura, dicionarios, catálogos, repertorios bibliográficos, biobibliografías, estudos monográficos, etc. A seguir, xerarquizamos este conxunto de referencias, traballando en primeiro lugar coas de carácter xeral, e atribuíndo un maior valor ás publicadas no período obxecto do noso traballo ou nos anos próximos -claramente a Literatura gallega de Eugenio Carré (1911)- ou a aquelas que demostraron maior fiabilidade canto aos datos que conteñen e que, por isto, gozan de maior recoñecemento no ámbito académico

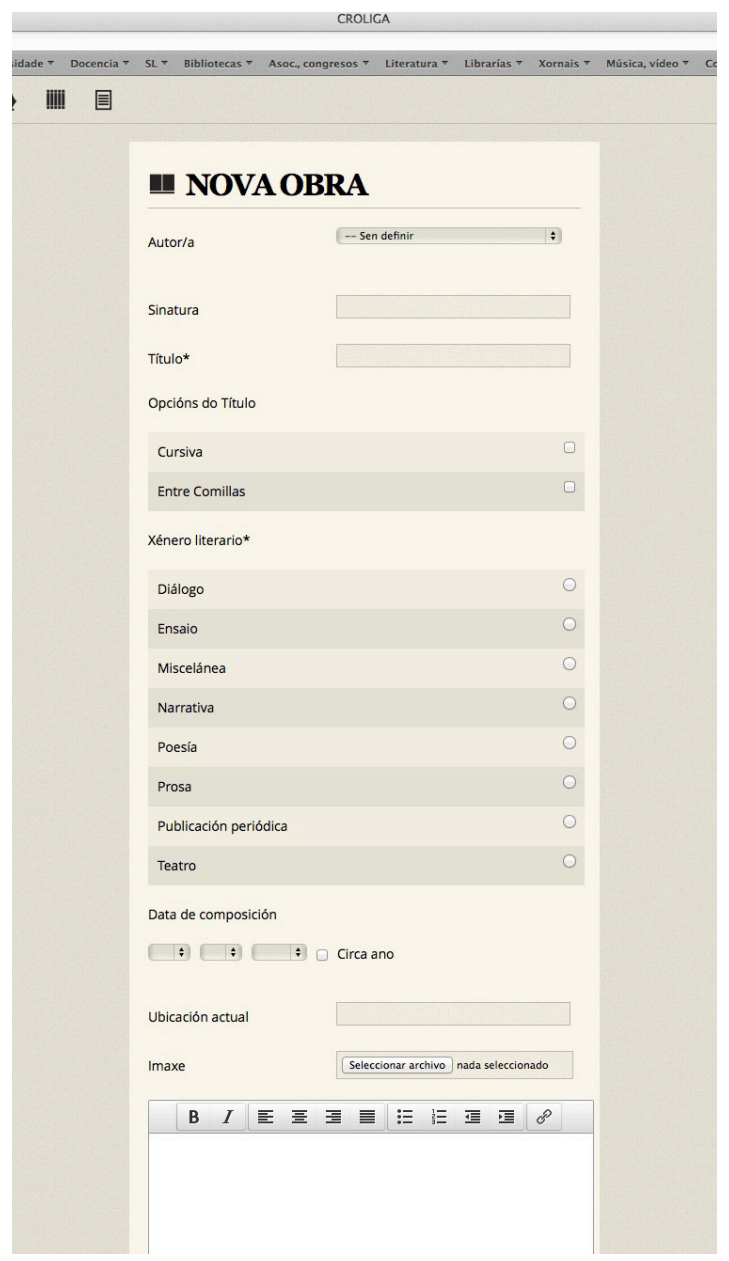

Figura 2
- o Diccionario bio-bibliográfico de escritores de Antonio Couceiro Freijomil (1951-53), ou a Historia da literatura galega contemporánea de Ricardo Carballo Calero (1981).

A continuación revisamos esta bibliografía secundaria para obter unha relación inicial dos volumes e das obras (e dos seus autores e das súas autoras) que forman parte da cronoloxía.

No inventario inicial de referencias bibliográficas foron incluídos volumes "atípicos" para o levantamento de títulos literarios mais que, dadas as características da transmisión e da difusión da literatura galega neste período, deben terse necesariamente en conta, como é o caso de gramáticas, antoloxías (manuscritas e impresas), volumes misceláneos, coleccións de artigos, coroas fúnebres, homenaxes, etc.

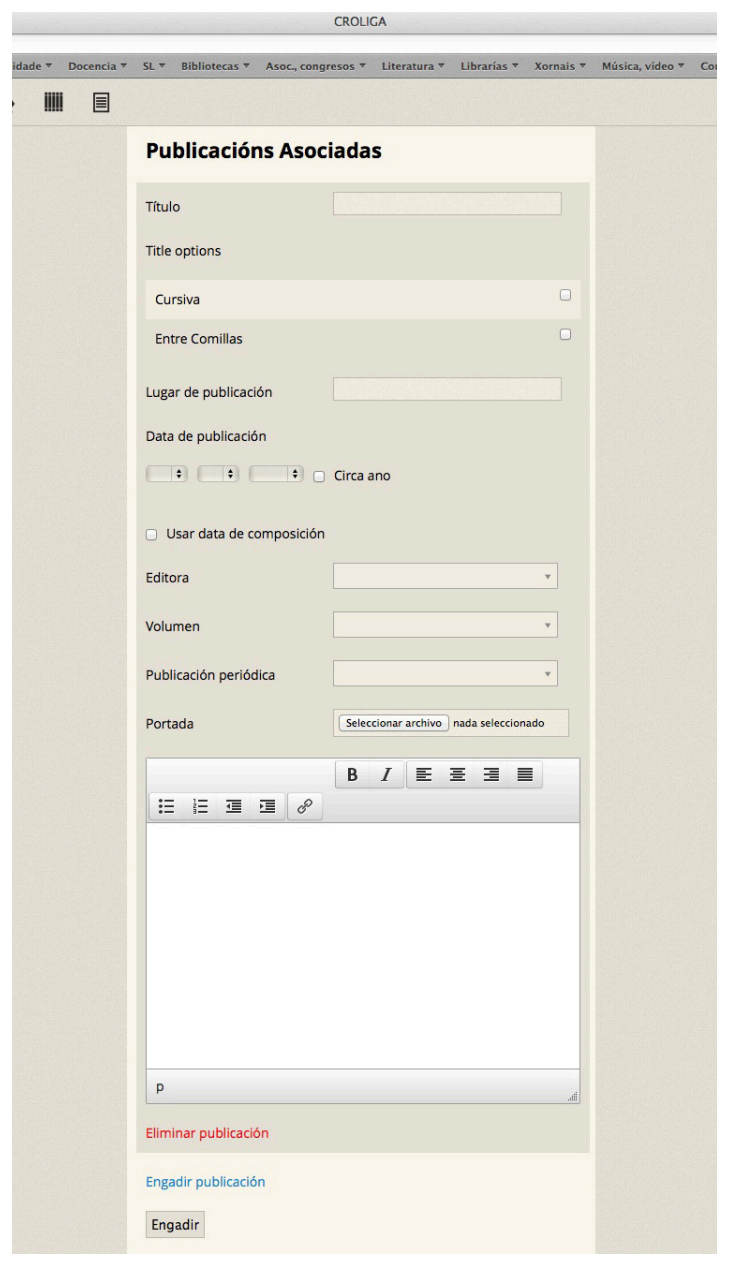

Figura 3 
que, en certa forma, están a medio camiño entre as referencias primarias e as secundarias. Exemplos significativos poden ser a Gramática gallega de Saco y Arce (1868); El idioma gallego. Su antigüedad y vida de Antonio de la Iglesia (1886); ou Esbozos y siluetas de un viaje por Galicia de Lisardo Barreiro (1890) que, en diferente medida, recollen obras literarias, nalgún caso compiladas ou publicadas aí por vez primeira.

Nesta fase detectamos xa algunhas dificultades que nos obrigaron a reorientar o traballo, principalmente para amplialo e completalo. A nosa intención era recoller como entradas individualizadas da cronoloxía cando menos todas as obras (poemas, contos, artigos, diálogos, etc.) que se difundiran (exclusivamente ou non) a través dunha publicación en libro no século XIX. Loxicamente, isto supuña incluír tamén na cronoloxía os volumes, de características materiais diversas, en que se publicaron os textos, cunha datación que podía coincidir ou non coa da/s obra/s en cuestión.

Desta forma pasaron a formar parte da cronoloxía todos os volumes que incluísen textos en lingua galega, independentemente de que estivesen escritos tamén ou maioritariamente noutra lingua (case sempre, en español). Así, figuran volumes como Rumores de los pinos de Eduardo Pondal (1877), as Poesías gallegas y castellanas de Francisco Añón (1889) ou Desde la reja. Cantos de un loco de Lamas Carvajal (1878) por incluíren todos eles textos en lingua galega ou, no caso pondaliano, poemas bilingües español-galego -en concreto, "La nostalgia de la nodriza" e "El recuerdo de la Patria", recollidos logo tamén en Queixumes dos pinos (Pondal 1886).
Por outra parte, aínda que a intención inicial era incluír na cronoloxía unicamente os textos que se editaran en volume con esta data de referencia, vimos a necesidade de ampliar esta información para dar conta tamén da súa data de composición - cando constase- e, sobre todo, para recoller as publicacións anteriores, moitas veces en xornais ou revistas. Como é sabido, foi este o medio principal de difusión da literatura galega no século XIX, a pesar de que o libro foi adquirindo importancia conforme avanzaba o século, principalmente a partir da década de oitenta, coa Biblioteca Gallega de Fernández Latorre y Martínez Salazar. Desta forma, na medida do posíbel, completamos a información de cada texto coas ocorrencias anteriores á súa publicación en volume ${ }^{6}$.

Logo surxiu a cuestión de que facer cos textos non publicados, nin en volume nin en ningún outro medio, mais que podían ser datados con certeza no período 1801-1900. Decidimos incluílos, de forma que textos inéditos no XIX, conservados como manuscritos autógrafos ou apógrafos, e logo editados no século $\mathrm{XX}$ ou mesmo no XXI, pasaron tamén a formar parte da cronoloxía. Desta forma, a "Égloga de Belmiro e Benigno" de Nicomedes Pastor Díaz, recuperada e publicada por Xosé Ma Álvarez Blázquez (Díaz 1951), ou a obra teatral A costureira d'aldea publicada en 2006 (Lugrís Freire 2006), pasaron a formar parte do noso corpus. E, dando un paso máis, pensamos que tamén era importante para o obxectivo da investigación incluír aquelas obras das que se ten noticia certa aínda que se continúe a descoñecer o texto, como pode ser o caso das obras premiadas en certames mais que non chegaron a publicarse, tal a comedia Amor e meiguería de Urbano González, galardoada nos Xogos Florais celebrados en Tui no ano $1891^{7}$.

\footnotetext{
${ }^{6}$ Para aquelas obras de que dispomos de edición crítica, esta tarefa vese notabelmente facilitada, pois podemos tomar as referencias das edicións e logo comprobalas. Non acontece así cun número relevante de obras das que non dispomos de edicións críticas (moitas veces tampouco de edicións contemporáneas). Por isto, e para ampliar e mellorar a cronoloxía, optamos por facer o baleirado sistemático dunha serie de publicacións especialmente relevantes para a cultura galega no XIX. Neste momento estamos a realizar a selección pois o baleirado sistemático de todas as publicacións, mesmo só as editadas en Galiza, está fóra do noso alcance neste momento.

${ }^{7}$ A relación de obras premiadas pode consultarse en “Juegos florales”, La Patria Gallega 7-8 (15/07/1891).
} 
Ao baleirar os volumes púxose a cuestión de como delimitar o que recibe (ou non) a consideración de "obra". Para os poemarios ou no caso de certas coleccións misceláneas, non existiu ningún problema mais, que facer cunha obra como A Gaita Gallega? É claro que o volume debe estar incluído na cronoloxía mais, que tratamento deben recibir os textos integrados nel? Aquí encontrámonos, por unha parte, coa tradición textual independente dalgúns textos, singularmente poemas, que forman parte d'A Gaita Gallega (Pintos 1853) mais que teñen unha transmisión previa propia -tamén posterior, mais isto é ben menos relevante, en termos xerais, do punto de vista da cronoloxía. Por agora, e neste caso concreto, optamos por incluír na cronoloxía como obras singularizadas ben as que figuran cun título propio neste volume, ben aquelas que se publicasen de forma independente con anterioridade como, por exemplo, "A usura", que cumpriría ambos os criterios ${ }^{8}$. Deixamos fóra da individualización na liña cronolóxica outros textos incluídos n'A Gaita Gallega que admiten unha lectura autónoma mais que non responden a ningún destes dous criterios.
E finalmente, debemos explicar unha cuestión central nesta investigación: o concepto de "obra literaria", aos efectos desta cronoloxía. Neste sentido, decidimos continuar coa praxe habitual na historiografía literaria galega, que inclúe os textos de propaganda política ou de finalidade didáctica dentro do seu obxecto de estudo, principalmente para os primeiros anos do século. Así, na cronoloxía figuran a "Carta recomendada" de Ramón González Serna (1812) ou La Tertulia de Picaños (Anónimo 1836), textos dun teor que para outros períodos serían considerados propiamente como produción escrita en lingua galega máis do que literaria.

Como presentará CROLIGA a información sobre cada obra? Vexámolo cun exemplo, o poema coñecido como "A campana d'Anllóns" (Figs. 4 e 5).

Como se pode comprobar nas Figs. 4 e 5, a obra está referenciada á súa data de publicación primeira e recóllense tamén as publicacións posteriores, en forma exenta ou incluídas en volume. Desde esta ficha accédese á información sobre o autor e ás fichas de cada unha das

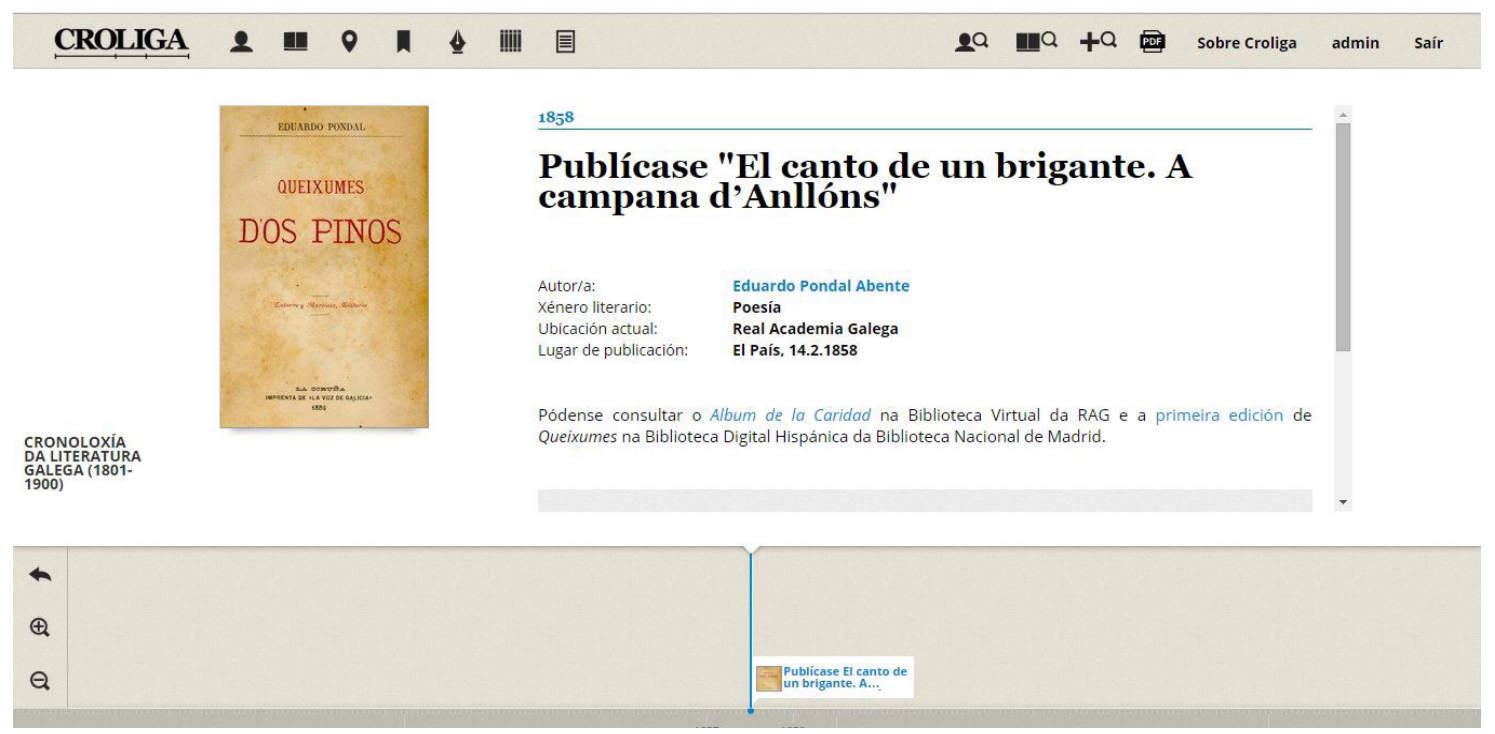

Figura 4

\footnotetext{
8 "A usura" publícase en 1845 en Misterios de Pontevedra por Un viejo de buen humor, que a los sesenta años de su vida empieza a escribir en verso por seguir el torrente de la moda (Amado 1845). En 1853 recóllese n'A Gaita Gallega.
} 


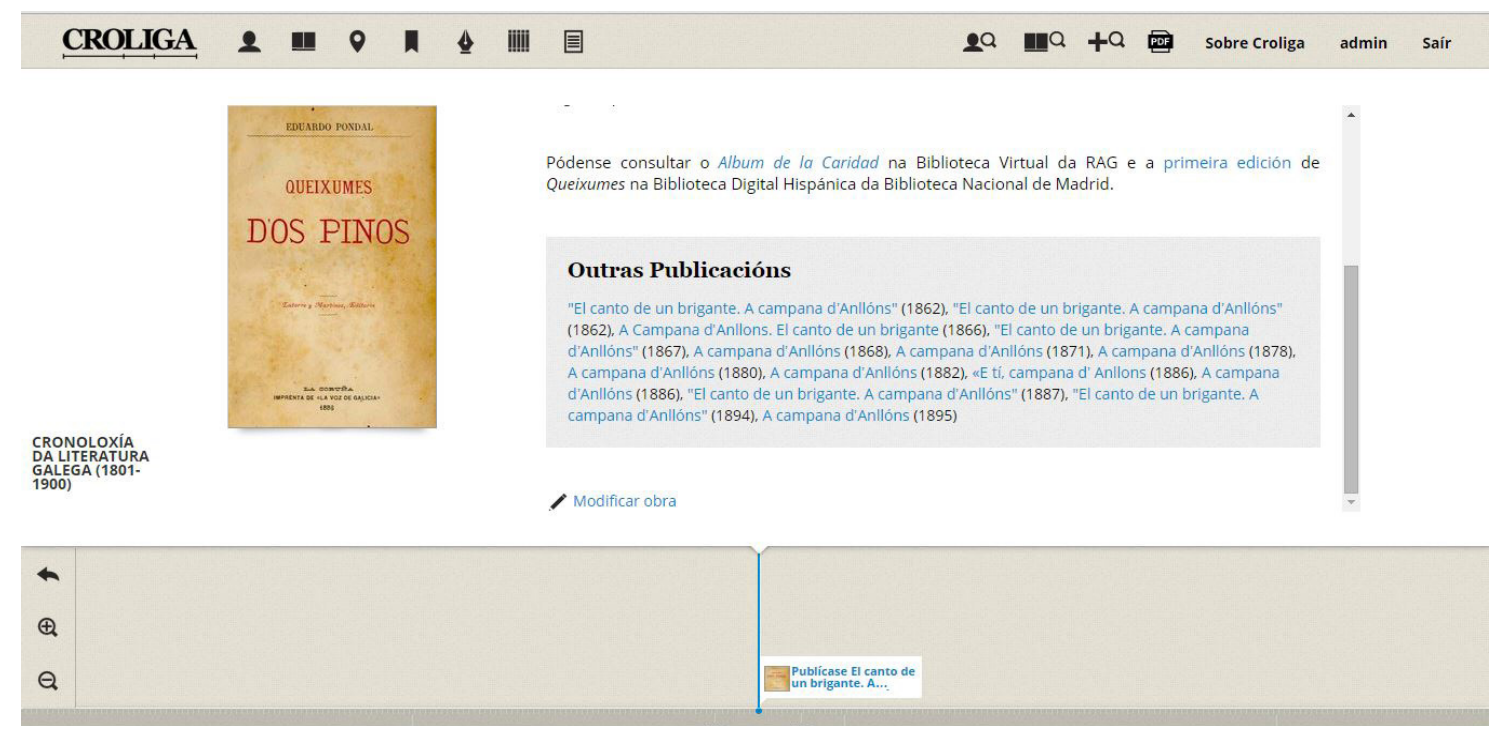

Figura 5

edicións da obra. Ademais, ofrécense enlaces ás edicións dixitais daquelas obras disponíbeis a día de hoxe en bibliotecas virtuais (neste caso, a do Álbum de la Caridad e a de Queixumes dos pinos, ambas accesíbeis na web da Real Academia Galega) ${ }^{9}$.

A inclusión de hipervínculos contribúe a achegar o portal ao concepto de repositorio, dado o crecente caudal de recursos disponíbeis en bibliotecas dixitais, e que, no relativo á literatura galega do século XIX, pretendemos centralizar en CROLIGA $^{10}$.

No campo de texto libre, podemos completar a información da obra, incluíndo explicacións adicionais, máis aló da que se proporciona a través dos campos predefinidos, para despexar calquera dúbida editorial ou ecdótica, por exemplo, recollendo o nivel de hipótese que nalgúns casos teñan os datos ofrecidos, e as bases en que se sustentan. A opción de incluír imaxes permítenos seleccionar a máis axeitada para cada obra.
Máis un exemplo: a ficha de "¡Adiós qu’eu voume!", o primeiro poema en galego de Rosalía de Castro (Figs. 6 e 7). Como se pode comprobar, na ficha recóllese a información sobre o poema na súa primeira publicación en El Museo Universal no ano 1861, e a referencia ás posteriores, en el Álbum de la Caridad (1862), Galicia. Revista Universal de este Reino (1862) e Cantares Gallegos (1863), nos primeiros casos citadas polo primeiro verso, no último, xa co título "Adios rios, adios fontes". Clicando en cada unha destas entradas, que figuran sob o rótulo "Outras publicacións", pode verse a referencia completa de cada unha delas.

De acordo cuns principios similares está elaborada a ficha autorial, que recolle información biográfica mínima (datas e lugares de nacemento e de falecemento), ademais das súas asinaturas literarias. Tendo en conta que nos movemos nun entorno dixital, decidimos utilizar as súas vantaxes e por iso, incluímos información gráfica. Utilizamos esta opción, até onde for posíbel, para recoller un retrato de

\footnotetext{
${ }^{9}$ Por defecto, figura a imaxe vinculada a Queixumes dos pinos, tan só unha das publicacións do poema. Neste momento estamos a axustar tecnicamente a plataforma para poder incluír imaxes singulares para cada publicación. Algo similar acontece co exemplo mostrado na Fig. 6.

${ }^{10}$ Ademais da Real Academia Galega, Galiciana, a Hemeroteca Nacional de Madrid, e a Biblioteca Digital Hispánica da Biblioteca Nacional de Madrid son bibliotecas dixitais con recursos notábeis para o período e o asunto da nosa investigación.
} 

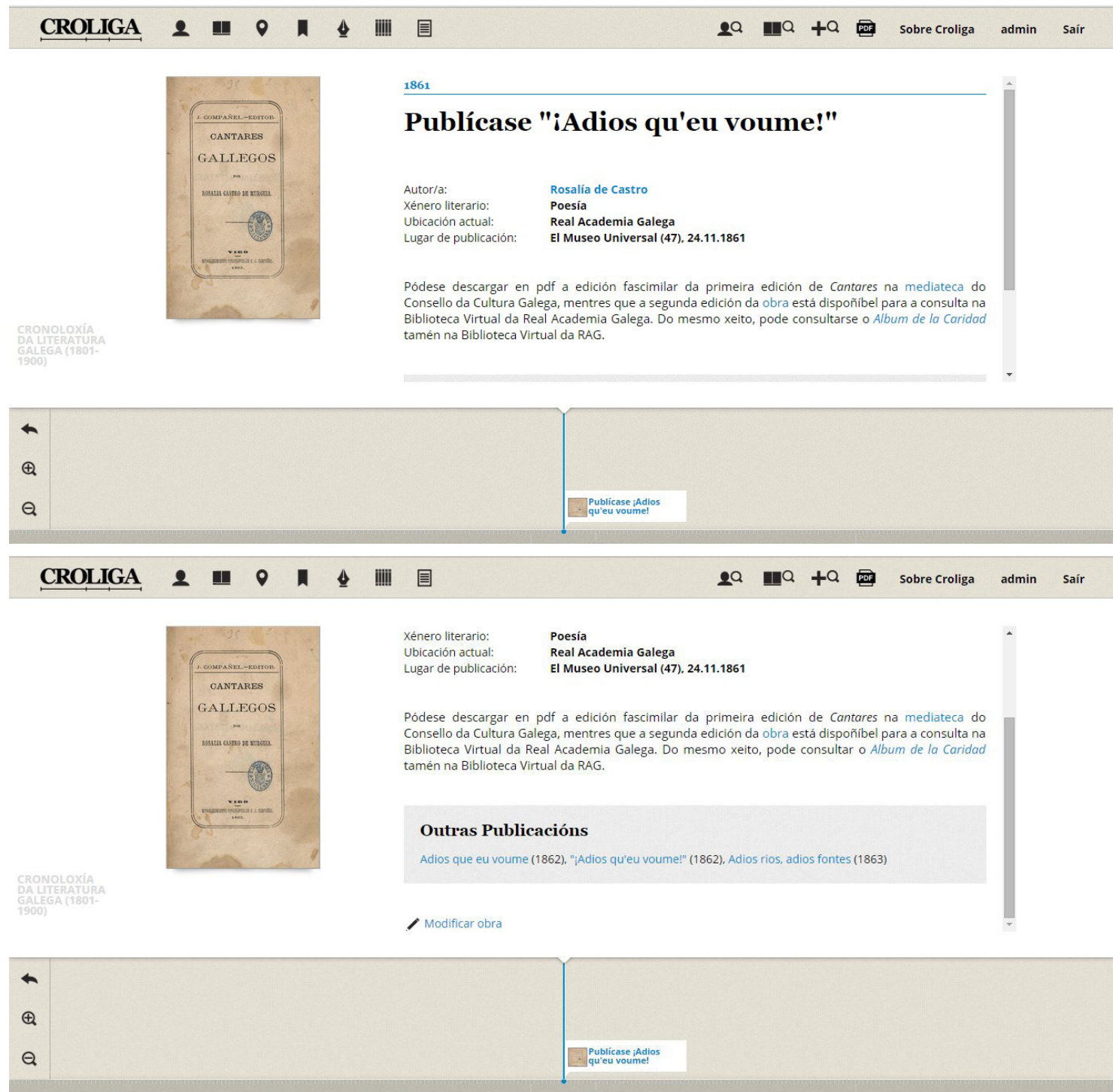

Figuras 6 e 7

cada autor ou autora, de forma que contribuiremos á fixación e difusión iconográfica dos escritores e das escritoras do século XIX, coas vantaxes - por exemplo, acrecentar o atractivo visual do portal web- mais tamén cos riscos que isto conleva ${ }^{11}$.
$\mathrm{Na}$ ficha autorial recóllense, ordenadas cronoloxicamente e agrupadas por ano, as súas obras. Clicando en cada unha delas, pode accederse á ficha respectiva, que contén a información tipo xa descrita nos parágrafos anteriores.

${ }^{11}$ Referímonos a que, nos casos onde exista a posibilidade de poder escoller entre varias opcións, teremos que optar por unha delas, de forma que esa opción estará a contribuír a consolidar (ou desbotar) unha certa imaxe física do escritor/a en cuestión. A este respecto, e para o caso de Rosalía de Castro, pode verse Pereira Bueno (2014). Por outra parte, a localización da información gráfica supón unha tarefa adicional sobre as inicialmente previstas. 
Inclúese tamén un campo de texto libre para poder achegar datos sumarios sobre cada autor ou autora e para, eventualmente, incluír algunha referencia, bibliográfica ou especificamente elaborada para a consulta on line, que permita ampliar de forma inmediata os datos seleccionados por nós. Por isto, este campo permite tamén a inclusión de hipervínculos.

Vexamos un exemplo de ficha de autor, nun estado de elaboración inicial e, por tanto, non definitivo (Fig. 8). Ao movermos a barra lateral van aparecendo as obras publicadas nos anos seguintes.

Como traballo en curso que é, por agora só temos resultados parciais. Mesmo as características que acabamos de expor poden verse modificadas consoante se vaia desenvolvendo o proxecto. A información que, a día de hoxe, se podería consultar no portal web, grosso mo$d o$, é a seguinte:

1. (Case) todos/todas os/as autores/autoras, con información básica: nome/asinaturas literarias, datas e lugares de nacemento e de falecemento.

2. (Case) todos os textos publicados en volume ou de forma exenta no período anterior a 1863.
3. Ademais, (case) todos os textos da autoría de Eduardo Pondal, Rosalía de Castro, Manuel Curros Enríquez, e Valentín Lamas Carvajal.

Neste momento estamos tamén a procurar solucións a problemas de diversa índole, tanto relativos ao deseño da base de datos como á súa presentación / visualización no portal web: por exemplo, o estabelecemento para cada volume dun vínculo que permita ofrecer a listaxe dos textos incluídos nel.

Outros asuntos nos que estamos a traballar son de carácter editorial nun sentido lato: afinar os criterios de edición, incorporar referencias críticas para cada texto, definir os criterios da incorporación de imaxes, etc. Dalgúns deles falamos xa nestas páxinas que, como explicamos de inicio, pretenden só presentar e mostrar algunhas características dun traballo en curso.

Esperamos que cando estea concluída, CROLIGA sexa unha ferramenta de consulta e de traballo, útil no ámbito académico, mais tamén para o público en xeral, e cuxa difusión aberta a través dun portal web favoreza o mellor coñecemento da literatura galega, alén fronteiras.

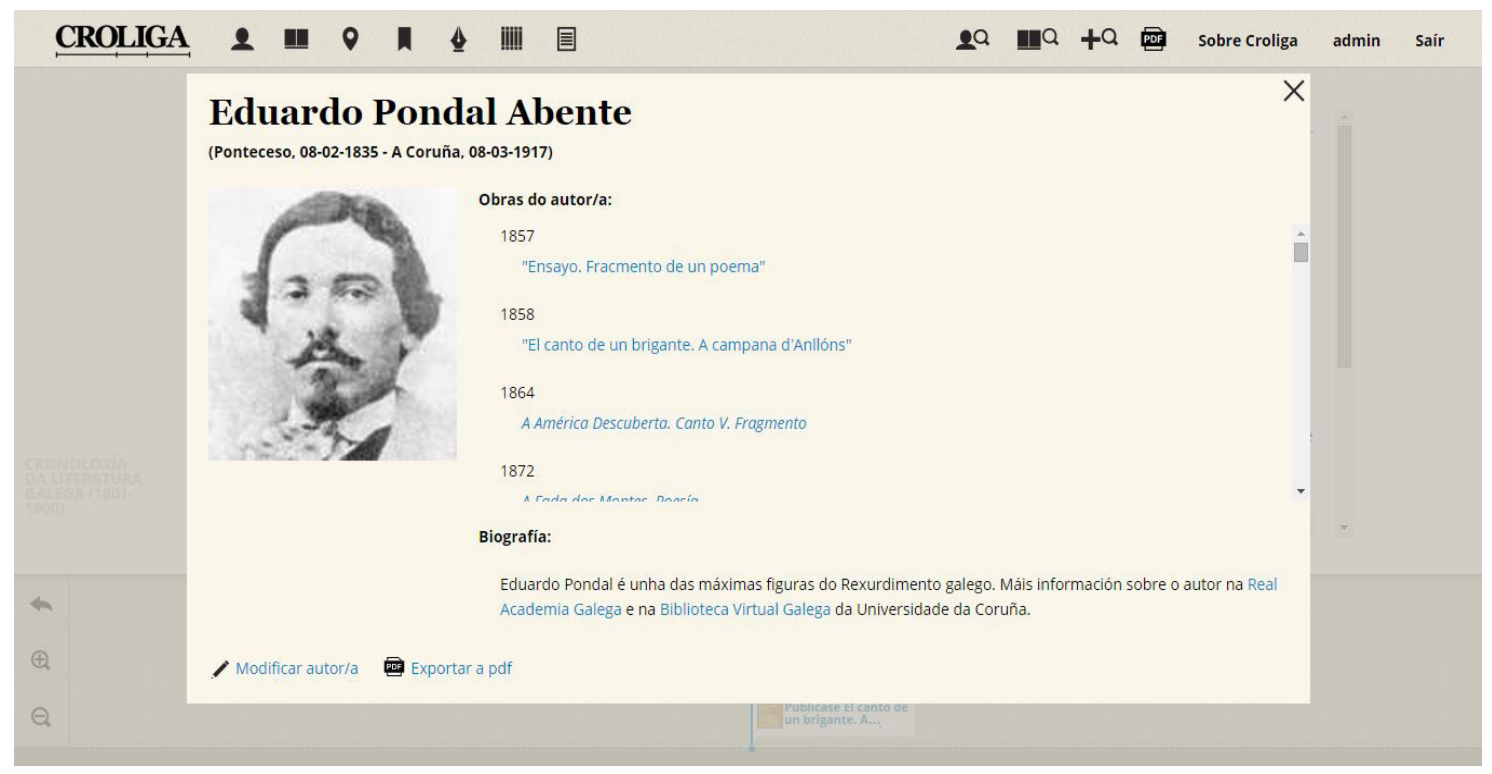

Figura 8 


\section{REFERENCIAS BIBLIOGRÁFICAS}

Amado, José Benito (1845): Misterios de Pontevedra. Pontevedra: Imprenta de Viuda de Pintos.

Anónimo (1836): La Tertulia de Picaños. Santiago: Imprenta de D. J. F. Campaña y Aguayo.

AÑón, Francisco (1889): Poesías gallegas y castellanas precedidas de un estudio acerca del poeta y sus obras por Victorino Novo y García. A Coruña: Andrés Martínez editor.

BARreIro, Lisardo (1890): Esbozos y siluetas de un viaje por Galicia. A Coruña: Andrés Martínez editor.

CARballo Calero, Ricardo (1981²): Historia da literatura galega contemporánea (1808-1936). Vigo: Galaxia.

CARRÉ Aldao, Eugenio (1911): Literatura gallega, con extensos apéndices bibliográficos y una gran antología de 300 trabajos escogidos en prosa y verso de la mayor parte de los escritores regionales. Barcelona: Maucci Editores.

Couceiro Freijomil, Antonio (1951-53): Diccionario bio-bibliográfico de escritores. Santiago de Compostela: Bibliófilos Gallegos, 3 vols.

De la Iglesia, Antonio (1886): El idioma gallego. Su antigüedad y vida. A Coruña: Latorre y Martínez editores.

DíAz, Nicomedes Pastor (1951): Poesías galegas (ed. Xosé Ma Álvarez Blázquez). Vigo: Edicións Monterrey.

GonzÁlez Serna, Ramón (1812): “Carta recomendada”, Gazeta Marcial y Política de Santiago 05/02/1812.

Lamas Carvajal, Valentín (1878): Desde la reja. Cantos de un loco. Colección de versos. Ourense: Imprenta de la Propaganda.

Lugrís Freire, Manuel (2006): A costureira d'aldea (ed. Teresa López). A Coruña: Universidade.

Pereira Bueno, Fernando (2014): Rosalía de Castro. Imaxe e realidade. Vigo: Xerais.

Pintos, Juan Manuel (1853): A Gaita Gallega tocada po lo Gaiteiro ou sea Carta de Cristus para ir deprendendo a ler, escribir e falar ben a lengua gallega, e ainda mais. Pontevedra: Imprenta de José y Primitivo Vilas.

Pondal, Eduardo (1877): Rumores de los pinos. Poesías. Santiago de Compostela: Tipografía de Manuel Mirás y Álvarez.

- (1886): Queixumes dos pinos. A Coruña: Latorre y Martínez, editores.

SaCo y Arce, Juan Antonio (1868): Gramática gallega. Lugo: Soto Freire. 